\title{
Diverse and abundant arbuscular mycorrhizal fungi in ecological floating beds used to treat eutrophic water
}

\section{Zhouying Xu}

Wuhan University of Technology

\section{Yichao LV}

Wuhan University of Technology

\section{Yinghe Jiang}

Wuhan University of Technology

\section{Xiaodong Luo}

Wuhan Municipal Construction Group Co., Ltd.

\section{Xuelin Gui}

Wuhan Municipal Construction Group Co., Ltd.

Yihui Ban ( $\nabla$ banyihui@whut.edu.cn )

Wuhan University of technology

\section{Research Article}

Keywords: Glomeromycota, AMF, Aquatic ecosystem, EFBs, Illumina sequencing, Community structure

Posted Date: March 12th, 2021

DOI: https://doi.org/10.21203/rs.3.rs-281997/v1

License: (c) (i) This work is licensed under a Creative Commons Attribution 4.0 International License. Read Full License 


\section{Abstract}

An increasing number of investigations have demonstrated the universal existence of arbuscular mycorrhizal fungi (AMF) in aquatic ecosystems. However, little is known about the accurate distribution and functions of AMF inhabiting aquatic ecosystems, especially ecological floating bed (EFB) which was constructed for the remediation of polluted waterbodies.

In this study, we collected root samples of Canna generalis, Cyperus alternifolius and Eichhornia crassipes from three EFBs floating on two eutrophic lakes in Wuhan, China, to investigate the resources and distribution of AMF in EFBs using Illumina Mi-seq technology. A total of 229 operational taxonomic units (OTUs) and 21 taxon from 348,799 Glomeromycota sequences were detected. Glomus was the most dominant AMF in the three EFBs while the second dominant AMF was related to Acaulospora. Different aquatic plant species exhibited varying degrees of AMF colonization (3.83\% 71\%), diversity (6 103 OTUs, 3 15 virtual taxa) and abundance (14 57551 sequences). Low AMF abundance but relatively high AMF diversity were found in $C$. alternifolius which is usually considered as nonmycorrhizal, demonstrating the high accuracy of Illumina sequencing. In addition, results from this study suggested a lognormal species abundance distribution was observed across AMF taxa in the three plant species, and the AMF community composition was closely related to $\mathrm{pH}$, nitrogen and phosphorus.

Overall, our data demonstrated that diverse and abundant AMF communities were living in EFBs, and the AMF community composition was closely related to the water quality of eutrophic lakes treated by EFBs, providing potential possibility for the applications of AMF in plant-based bioremediation of wastewater.

\section{Introduction}

Arbuscular mycorrhizal fungi (AMF) are an ancient group of root symbionts whose origin synchronized with the occurrence of terrestrial plants [1]. The AM symbiosis involves $~ 80 \%$ of terrestrial plants and 250 morphologically defined or 350 1000 molecularly defined AMF [2, 3]. It benefits plant establishment by improving plant nutrient acquisition and soil quality, promoting the adaptability of plants under various stress conditions and enhancing the stability of hosts community structure [4].

Although AMF are extensively studied in terrestrial ecosystems, they are poorly documented in aquatic ecosystems. In previous studies, it was considered that AMF had little significance in aquatic ecosystems [5-8]. The conclusion may be based on the restricted oxygen in saturated aquatic soils, which is detrimental to the survival of AMF [9]. In addition, submerged and floating aquatic species can obtain inorganic nutrients from the water as well as the substrate, through both shoot and root surfaces [10], therefore, the aquatic plants may don't rely on AMF for the nutrients. Over the last two decades, an increasing number of investigations have demonstrated the existence of AMF in aquatic ecosystems. As reviewed in previous work, AM symbiosis has been found in 99 families of wetland plants, even in submerged aquatic plants, from various aquatic and wetland habitats [11]. Several wetland plant species (e.g., Cyperaceae, Chenopodiaceae, and Plumbaginaceae), which are generally considered as non- 
mycorrhizal plants [12], have been demonstrated to have high levels of AMF colonization in their roots $[13,14]$. Therefore, the distribution and function of AMF inhabiting in aquatic ecosystems need to be furtherly investigated.

Most studies on AMF diversity in aquatic ecosystems were performed using morphological method [15, 16]. Only a few researches were conducted by molecular approaches, including restriction fragment length polymorphism (RFLP) [17], temporal temperature gradient gel electrophoresis (TTGE) [18], denaturing gradient gel electrophoresis (DGGE) [19], clone libraries [20], and single stranded conformation polymorphism (SSCP) [21]. However, the biggest limitation of these methods is that they focus on only the dominant AMF taxa in complex microbial communities and are difficult to detect relatively low abundance AMF taxa[22-24]. Their lack of resolution may lead to the neglect of the rare species and onesided conclusions. In recent years, next generation sequencing (NGS) technologies have been applied to the researches of AM fungal community due to its comprehensiveness and accuracy in analyzing soil microbial community structure, however, only a few studies have focused on AMF in wetland and lakebed habitats $[25,26]$.

Ecological floating bed (EFB) is a promising ecological engineering tool for restoring polluted (eutrophic [27-29], organic polluted [30], heavy metals polluted [31] and so on) waterbodies. It has many advantages, including small land occupied, little influence by water level fluctuation, convenient management, economical and efficient, and also with a good landscape effect [32]. The ecological functions of EFBs have been studied in situ, mesocosms and the laboratory. As we known, there is only one paper reported the AMF diversity in EFBs using morphological method by Stenlund and Charvat [33], and they found low levels of AMF were present in EFBs.

In the present study, root samples of aquatic plants were collected from three EFBs on two eutrophic lakes located in Hubei Province of China, to investigate AM fungal community structure in EFBs treating eutrophic lake water using Illumina Mi-seq technique. The purpose of our study is to explore the resource and distribution of AMF in EFBs planted with mycorrhizal plant species, and to verify if AMF existed in roots of plant species which were considered non-mycorrhizal by morphological identification. We hypothesized that the roots of aquatic plants inhabiting in EFBs harbored high diversity and abundance of AMF, and different aquatic plant species exhibited varying degrees of AMF colonization, diversity and abundance.

\section{Materials And Methods}

\subsection{Study area description and sampling}

Donghu Lake and Nanhu Lake locate in the northeast of Wuhan which is the largest city in central China. Donghu Lake is the largest urban lake in Wuhan, covering an area of $33.7 \mathrm{~km}^{2}$, with an average depth of $2.8 \mathrm{~m}$ and a maximum depth of $4.8 \mathrm{~m}$. Nanhu Lake, the third largest urban lake in Wuhan, covers an area of $7.6 \mathrm{~km}^{2}$ and has a maximum depth of $3.2 \mathrm{~m}$. In the 1990s, with the rapid development of 
industrialization and urbanization in Wuhan, anthropogenic activities became increasingly frequent. Large quantities of industrial wastewater, agricultural effluents, sewage and domestic wastewater were directly discharged into Donghu Lake and Nanhu Lake without treatment. The discharge of excessive inorganic nutrients (i.e., nitrogen and phosphorus) led to eutrophication, algal blooms and habitat degradation in the two lakes. To restore the ecosystem structure and reduce the eutrophication of Donghu and Nanhu Lake, the local government had constructed some EFBs on the two lakes. The constructed EFBs were composed of hundreds of small ecological floating plates $(0.5 \mathrm{~m} \times 0.5 \mathrm{~m})$, in which aquatic plants from different nursery companies were planted. A total of three kinds of plant species (Canna generalis, Cyperus alternifolius and Eichhornia crassipes) were found on these EFBs, and the solid substrate of the EFBs were mostly silt and ceramic. Although EFBs had been in operation for many years, the aquatic plants in the floating bed still growing well.

The first EFB $(30 \mathrm{~m} \times 30 \mathrm{~m})$ in Donghu Lake $\left(30^{\circ} 34^{\prime} 39^{\prime \prime} \mathrm{N}, 114^{\circ} 22^{\prime} 12^{\prime \prime} \mathrm{E}\right)$ was divided into two parts according to the species of aquatic plants. One part was planted with Canna generalis (EA) and the other part was planted with Cyperus alternifolius (EB). Root samples were collected from three sites (EA1, EA2 and $E A 3)$ in $E A$ and three sites (EB1, EB2, and EB3) in EB, and each sampled site was at least $5 \mathrm{~m}$ apart from the other. No sampling was conducted at the boundary between the two parts. The second EFB (20 $\mathrm{m} \times 20 \mathrm{~m}$ ) planted with $C$. generalis $(\mathrm{SA})$ and the third EFB $(20 \mathrm{~m} \times 20 \mathrm{~m})$ planted with Eichhornia crassipes (SB) in Nanhu Lake (30 $\left.30^{\prime} 21^{\prime \prime} \mathrm{N}, 114^{\circ} 20^{\prime} 39^{\prime \prime} \mathrm{E}\right)$ were selected to collect the roots. Root samples were collected from three sites (SA1, SA2 and SA3) in SA and three sites (SB1, SB2 and SB3) in SB, and each sampled site was at least $5 \mathrm{~m}$ apart from the other. Sampling was conducted in Feb. 2019. In each site (12 sites in total), five individual plants were randomly selected and dug out from a regularly spaced grid $(4 \times 4 \mathrm{~m})$ and the roots from five individuals were pooled and used as a composite root sample. A total of 60 individual plants were collected from the three EFBs. Each sample was collected with disposable equipment to avoid cross-contamination. Care was taken to collect only fine young roots, as this is where most mycorrhizal colonization occurs [34]. All the samples were stored on ice and then transported to the laboratory. Roots of each sample were washed and rinsed with sterile water, dried on paper towels, and then divided into two parts. One part of the root samples was fixed in FAA solution (Formalin $5 \mathrm{ml}+$ Glacial acetic acid $5 \mathrm{ml}+70 \%$ Alcohol $90 \mathrm{ml}$ ) to detect the mycorrhizal colonization, and another part of roots was stored at $-80^{\circ} \mathrm{C}$ for later DNA extraction. Water samples near the roots were also collected to evaluate the water quality at the same time.

\subsection{Determination of water quality}

The on-line parameters including temperature ( $T$ ), dissolved oxygen (DO), pH, electrical conductivity (EC), specific conductance (SC), atmosphere pressure (AT), total dissolved solids (TDS), salinity (S) and redox potential (ORP) were measured in situ with a YSI 6600 V2 multiparametric sonde (Yellow Spring Instruments, USA). The laboratory analysis involving chemical oxygen demand (COD), ammonia nitrogen $\left(\mathrm{NH}_{4}{ }^{+}-\mathrm{N}\right)$, nitrate nitrogen $\left(\mathrm{NO}_{3}{ }^{-}-\mathrm{N}\right)$, nitrite nitrogen $\left(\mathrm{NO}_{2}{ }^{-} \mathrm{N}\right)$, total nitrogen (TN), inorganic phosphorus (IP) and total phosphorus (TP) was completed in the lab according to the standard methods [35]. 


\subsection{AM fungal colonization analysis}

After rinsed with sterile water, roots stored in FAA solution were cut into $1 \mathrm{~cm}$ fragments and then stained according to the modified method of Phillips and Hayman [36]. Overall, 30 root fragments of $1 \mathrm{~cm}$ per sample were used to measure the mycorrhizal colonization under a light microscope (Olympus Bx51, Japan) at $200 \times$ magnification. The frequency of mycorrhiza ( $F \%)$, intensity of the mycorrhizal colonization $(\mathrm{M} \%)$, and the arbuscule abundance in the root system $(A \%)$ were calculated according to Trouvelot et al. [37]. The $M \%$ was based on a five-class system ranking: rare $\left(n_{1} ;<1 \%\right)$, low $\left(n_{2} ; 1 \sim 10 \%\right)$, medium $\left(n_{3} ; 11 \sim 50 \%\right)$, high $\left(n_{4} ; 51 \sim 90 \%\right)$ and abundant $\left(n_{5} ; 91 \sim 100 \%\right)$. The $A \%$ was based on a threeclass system ranking: low $\left(A_{1} ;<10 \%\right)$, medium $\left(A_{2} ; 11 \sim 50 \%\right)$ and high $\left(A_{3} ; 51 \sim 100 \%\right)$.

$\mathrm{F} \%=\left(\mathrm{n}_{\mathrm{b}} / 30\right) \star 100$

where $n_{b}$ is the number of fragments with colonization by AMF.

$M \%=\left(\left(0.95 n_{5}+0.7 n_{4}+0.3 n_{3}+0.05 n_{2}+0.01 n_{1}\right) / 30\right) * 100$

where $n_{1}, n_{2}, n_{3}, n_{4}$ and $n_{5}$ are the number of root fragments at each level of colonization intensity.

$m \%=M * 30 / n_{b}$

$\mathrm{a} \%=\mathrm{mA}_{3}+0.5 \mathrm{~mA}_{2}+0.1 \mathrm{~mA}_{1}$

where $A_{1}, A_{2}, A_{3}$ are the number of root fragments at each level of arbuscule

abundance; $\mathrm{mA}_{3}, \mathrm{~mA}_{2}, \mathrm{~mA}_{1}$ are the $\%$ of $m$, rated $\mathrm{A}_{3}, \mathrm{~A}_{2}, \mathrm{~A}_{1}$, respectively,

with $m A_{3}=\left(\left(0.95 n_{5} A_{3}+0.7 n_{4} A_{3}+0.3 n_{3} A_{3}+0.05 n_{2} A_{3}+0.01 n_{1} A_{3}\right) / n_{b}\right){ }^{\star} m$, and the same for $A_{2}$ and $A_{1}$.

$A \%=(a * M) / 100$

\subsection{DNA extraction and PCR amplification}

The methods to extract microbial DNA and amplify the AM fungal 18S ribosomal RNA genes were the same as those used in our previous studies [38, 39]. The primers used in the nested PCR reaction were AML1 (5'- ATCAACTTTCGATGGTAGGATAGA-3')/AML2 (5'- GAACCCAAACA CTTTGGT

TTCC-3') [40], and AMV4.5NF (5'-barcode-AAGCTCGTAGTTGAATT

TCG-3')/AMDGR (5'-CCCAACTATCCCTATTAATCAT-3') [41, 42]. The yielded amplicons of the nested PCR were 800 and $300 \mathrm{bp}$, respectively. All PCR amplifications were performed in triplicate, and please refer to the supplemental material for the detail parameters. 


\subsection{Illumina sequencing}

The methods of extraction, purification and quantification of PCR amplicons were the same as those used in our previous study [38]. Purified amplicons were pooled in equimolar and paired-end sequenced $(2 \times 250)$ on an Illumina MiSeq platform (Personalbio, Shanghai, China) according to the standard protocols [43]. The raw reads were deposited into the NCBI Sequence Read Archive (SRA) database (Accession Number: PRJNA550311).

\subsection{Processing of sequencing data}

QIIME (version1.9.1) was used to demultiplex and quality-filter the raw data (FASTQ files) [44] with some criteria, please refer to the supplementary material for the detail criteria. The methods to cluster the Operational Units (OTUs), identify and remove chimeric sequences, identify the representative OTUs, evaluate the richness index, compute the overdominance $(O)$ and inequitability $(I)$, determine the form of the taxon abundance distribution and conduct SHE analysis were the same as those in our previous study [39]. We calculated the value $(P i-P e) / P e$ to quantify the highlights of taxon dominance in the communities [45], where $P i$ denote the relative abundance of OTU $i$, and $P e$ is calculated as the ratio of 1 to the total OTU number, i.e. all the OTUs in a perfectly even community have the same relative abundance. The value $(\mathrm{Pi}-\mathrm{Pe}) / \mathrm{Pe}$ of the top-ranked OTU was denoted as "overdominance" $\mathrm{O}$, and the proportion of OTU with a negative value $(P i-P e) / P e$ was denoted as "inequitability" I. SHE analysis of the whole AMF assemblage was also carried out in this study using $S$ (observed richness) and $H^{\prime}$ (Shannon entropy) generated from rarefaction estimates by EstimateS, the $E_{\mathrm{BG}}$ (equitability index) calculated from $S$ and $H^{\prime}$. The representative OTUs were classified against the MaarjAM database and NCBI database on Jan 2020.

\subsection{Statistical analysis}

The rarefaction analysis of data subsets was conducted using the software of Mothur (version 1.30.1). The Venn graph, line graph and pie chart were performed using R language tool and SigmaPlot V10.0 (Systat Software, San Jose, CA). The non-metric multidimensional scaling (NMDS, using vegan package in $\mathrm{R}$ ) and permutational multivariate analysis of variance (PERMANOVA, using the adonis function in vegan) were used to partition variance in the 12 AM fungal communities. UniFrac dissimilarity [46] was calculated by QIIME [44] and used as a measure of distance between pairs of AM fungal communities. Significant differences in AMF abundance at genus levels between the 4 groups were detected by employing a one-way analysis of variance (ANOVA) $(P<0.05)$. Redundancy analysis (RDA) were conducted to determine the multivariate relationship between $A M$ fungal community and environmental factors using the software Canoco (version 4.5, Centre for Biometry, Wageningen, The Netherlands), the effect and significance of each environmental factor on the microbial communities were evaluated using forward selection and the Monte Carlo permutation test (499 replicates). 


\section{Results}

\subsection{AM fungal colonization in the roots of aquatic plants inhabiting in EFB}

The F\% of EA (C. generalis in Donghu Lake), EB (C. alternifolius in Donghu Lake), SA (C. generalis in Nanhu Lake) and SB (E. crassipes in Nanhu Lake) were $100 \%, 13.33 \%, 70 \%$ and $96.67 \%$, respectively. The $\mathrm{M} \%$ of EA, EB, SA and SB were $68.83 \%, 3.83 \%, 9.73 \%$ and $71 \%$, respectively, and the A\% were $6.06,0,0$ and $6.89 \%$, respectively.

\subsection{Water qualities}

The water qualities of the collected samples were shown in Table 1 and 2 . The water quality parameters measured in Donghu Lake (EA and EB) were significantly different from that in Nanhu Lake (SA and SB), except COD concentration. The water qualities of EA and EB were identical for the reason that they were collected from the same EFB in Dong Lake. The water qualities of SA and SB were significantly different for the reason that they were collected from two different EFBs in Nanhu Lake. As shown in Table 1, the TN and TP concentrations of the water samples that collected from the two lakes far exceeded the minimum criteria for eutrophication ( $\mathrm{TN}>0.2 \sim 0.3 \mathrm{mg} / \mathrm{L}, \mathrm{TP}>0.01 \sim 0.02 \mathrm{mg} / \mathrm{L}$ ), indicating that the water was in a status of severe eutrophication. The water samples from EA and EB showed higher levels of TN, $\mathrm{NH}_{4}{ }^{+}-\mathrm{N}, \mathrm{NO}_{2}{ }^{-}-\mathrm{N}$, TP and IP concentrations than those from SA and SB. SB exhibited lowest TN and IP concentrations, while SA had lowest $\mathrm{NH}_{4}{ }^{+}-\mathrm{N}$ and $\mathrm{NO}_{2}{ }^{-}{ }^{-} \mathrm{N}$ concentrations. As shown in Table 2, EA and EB showed highest values of T, EC, TDS, SC, $S$ and lowest values of $\mathrm{pH}, \mathrm{ORP}$, and DO.

\subsection{AM fungal communities in EFBs}

\subsubsection{Overall MiSeq sequencing information}

To characterize the AM fungal communities in the aquatic plant roots living in the three EFBs, 12 root samples of the three aquatic plant species were sequenced on an Illumina MiSeq. 650,793 clear sequences were obtained and clustered into 1087 OTUs at the $97 \%$ sequence similarity level.

\subsubsection{AM fungal community richness and species accumulation curves analysis}

As shown in Table 3, after removing the singletons, the total number of Glomeromycota sequences obtained from Illumina sequencing reads was estimated to be 348,799 (53.60\% of all sequences, 229 OTUs), of which, 333,963 (96.50\% of all Glomeromycota sequences, 218 OTUs) sequences could be classified into 19 virtual taxa (VTs) of the MaarjAM database. The remaining 12216 (3.50\% of all Glomeromycota sequences, 11 OTUs) sequences could not be classified to groups of known sequence represented in the MaarjAM database, but got hits of 2 AMF taxa (Glomus sp. MH559174.1, 
Archaeospora sp. MH559177.1) against NCBI database (Table S1). The VTs numbers assigned against Maarj $A M$ database using the data with singletons was same as those using the data without singletons (Table S2 and Table S3). The AMF composition of which relative abundance higher than $1 \%$ in each community was shown in Table S4.

The species accumulation curve of AMF in the aquatic plants root living in the three EFBs reached an asymptote (Fig. S1), indicating that the sampling intensity was adequate, so did the curve of AMF data with singletons (Fig. S2).

As shown in Fig. 1,71\% (246763) of the sequences and 83\% (190) of the OTUs belonged to Glomus. $28 \%$ (99288) of the sequences and 15\% (34) of the OTUs belonged to Acaulospora. $6.31 \mathrm{e}^{-3 \%}$ (22) of the sequences and $1 \%$ (2) of the OTUs belonged to Claroideoglomus. 1\% (2726) of the sequences and 1\% (3) of the OTUs belonged to Archaeospora. Therefore, most of the AMF species obtained from the three EFBs belonged to Glomus, followed by Acaulospora. The proportional distributions of AMF data with singletons was similar (Fig. S3).

\subsubsection{AMF assemblages in the different samples}

As shown in Fig. 2, Glomus were the dominant in the 12 samples except SB2, which was dominated by Acaulospora (99.94\%). As shown in Fig. S4, Glomus was the dominant genus in the 4 groups except SB, which was with a dominance of Acaulospora (63.05\%). The same results were obtained with the database with singletons (Fig. S5, Fig. S6).

As shown in Table 3, the numbers of Glomeromycota sequences ranged from 14 (EB1) to 57551 (SB2), forming 6 (SA1) to 103 (EA2) OTUs and 3 (SA3, EB2) to 15 (SA2) VTs. The total numbers of AMF sequences, OTUs and VTs identified in EB1 were 14, 8 and 4, respectively, while those were 31, 8 and 5 in EB3, respectively. The data in Table S5 indicated that AM fungal communities with low abundance but high diversity existed in EB1 and EB3, and the low abundance was not attribute to the sequencing errors. Comparing with EB1 and EB3, EB2 showed much higher abundance, and had a dominant OTU, which accounting for $92 \%$ sequences (OTU 397, 43748 sequences, assigned as Glomus LES06 VTX00310). Comparing with SA1 and SA2, SA3 had much more sequences due to the dominant OTU 914 (5064 sequences), which had no hits in Maarj $A M$ database but assigned as Glomus sp. in NCBI database (MH559174.1). Comparing with SA1 and SA3, SA2 exhibited a significantly higher number of OTUs and VTs.

As shown in Fig. S7, EA1, EA2 and EA3 shared 4 common VTs (Glomus VTX00113, Glomus VTX00114, Glomus VTX310, Glomus VTX419), and 1 common NCBI taxon (Glomus sp. MH559174.1), representing $100 \%, 83 \%$ and $83 \%$ of their total taxa, respectively. EB1, EB2 and EB3 shared 3 common VTs (Acaulospora VTX00028, Glomus VTX00310, Glomus VTX00114), representing 75\%, 75\% and $50 \%$ of their total taxa, respectively. SA1, SA2 and SA3 shared 2 common VTs (Glomus VTX00114, Acaulospora VTX00028), representing $50 \%, 12.5 \%$ and $50 \%$ of their total taxa, respectively. SB1, SB2 and SB3 shared 5 
common VTs (Acaulospora VTX00028, Acaulospora VTX00029, Glomus VTX00093, Glomus VTX00114, Glomus VTX00419), representing $83 \%, 62.5 \%$ and $50 \%$ of their total taxa, respectively.

As shown in Fig. S8, EA, EB, SA and SB shared 4 common VTs (Glomus VTX00114, Glomus VTX00113, Glomus VTX00310, Glomus VTX00419), representing $57 \%, 57 \%, 21 \%$ and $36 \%$ of their total VTs, respectively. No single VT was common to all 12 samples None fungal taxa were detected in all the 12 samples. According to the metastats analysis (Table 4), significant differences existed between EA and EB for Glomus. Significant differences existed between SA and SB for Glomus and Acaulospora abundance. Significant differences existed between EA and SB for Glomus and Acaulospora abundance. Significant differences existed between EB and SB for Glomus and Acaulospora abundance. Similar metastats analysis results for data with singleton was showed in Table S6.

NMDS ordinations of unweighted UniFrac compositional dissimilarities and PERMANOVA results indicated that the AM fungal communities in the three EFBs could be significantly separated with $P$ values of 0.002 (Fig. 3). AM fungal communities data with singletons in the three EFBs could also be significantly separated with $P$ values of 0.003 (Fig. S9).

As shown in Fig. 4a, the AM fungal communities of the four group samples in the levels of Diversisporales, Acaulosporaceae, Acaulospora, Glomerales, Glomeraceae and Glomus were significantly different $(P<0.05)$. For Acaulospora, the sample SB has the highest and EA has the lowest relative abundance, for Glomus, the sample EA has the highest and SB has the lowest relative abundance (Fig. $4 b, c)$.

\subsubsection{Taxon abundance distributions}

In order to differentiate between the fit of several theoretical taxon abundance distribution models to the whole (12 samples together) data, we used the index of Akaike Information Criterion (AIC) and found the lognormal model fits the observed data better $(\mathrm{AIC}=112,516)$ than the niche preemption (geometric series) model $($ AIC $=212,343)$, Zipf model $($ AIC $=212,004)$, and broken stick model $($ AIC $=1331,638)$ (Fig. 5). For the four groups, EA and SB showed best fit to lognormal model, however, EB and SA showed best fit to Zipf model (Fig. S10). For the data with singletons, the similar results were obtained (Fig. S11, Fig. S12). The results of $S H E$ analysis showed that $\ln (S)$ and $\ln (H)$ increased slowly as the number of sequences increased, while $\ln \left(E_{\mathrm{BG}}\right)$ declined slowly to flat and $\ln \left(E_{\mathrm{BG}}\right) / \ln (S)$ remained flat as the number of sequences increased from early to late (Fig. S13). As reported by Magurran [47], this particular pattern is the character of a lognormal species abundance distribution. Based on the comprehensive judgment of all the analysis results, we concluded that the AMF abundance distribution in the three EFBs was lognormal. Similar SHE analysis results were found in data with singletons (Fig. S14)

\subsubsection{Overdominance and inequitability}

As shown in Fig. S15, across the landscape, the most abundant taxon OTU393 (Acaulospora Alguacil10 Aca2 VTX00028) was more than 35 times $(O=35.18)$ as abundant as it would be in an even community, 
and $89 \%$ of the OTUs were less abundant than in such a perfectly even community $(I=0.89)$. To assess the importance of the most abundant OTU in the AM fungal communities inhabiting in the three EFBs, the abundance ratio of most abundant OTU to second-most (1:2) was calculated to be 1.2 , and the ratio of most abundant OTU to third-most (1:3) was calculated to be 1.6. In the four groups, the $O$ ranged from 39.46 in group EB, where the relative abundance of the most abundant taxon OTU397 (Glomus LES06 VTX00310) was $92 \%$ and richness was 43768 , to 21.24 in group EA, where the relative abundance of the most abundant taxon OTU960 (GlomusirregularVTX00114) was 17\% and richness was 23600 (Fig. S16).

\subsubsection{Relationships between AMF community and environmental variables}

In this study, according to the RDA results (Fig. 6), different environmental variables had differential effects on AMF community. the eigenvalues of axes 1 and 2 were 0.4222 and 0.2105 , respectively, explaining $42.22 \%$ and $21.05 \%$ of the AMF-environment relationship variance. The TN, TP, IP, $\mathrm{NH}_{4}{ }^{+}-\mathrm{N}^{-} \mathrm{NO}_{3}{ }^{-}$ $-\mathrm{N}, \mathrm{DO}$ and $\mathrm{pH}$ had significant effects on the AMF community composition, among which, $\mathrm{pH}$ was the most prominent factor. SB was located in the first quadrant, while EA, EB and SA were located in the second quadrant. EA, EB and part of SA (SA1 and SA3) were positively correlated with TN, TP, IP and $\mathrm{NH}_{4}{ }^{+}-\mathrm{N}$, and $\mathrm{SB}$ was positively correlated with $\mathrm{pH}$.

\section{Discussions}

\subsection{AM fungal colonization in aquatic plant roots living in EFBs}

In previous studies, $C$. generalis was found to be colonized by AMF both in terrestrial and aquatic habitats [19, 48-50], and E. crassipes can also form a mutualistic symbiosis with AMF [51-53]. The association between $\mathrm{AMF}$ and $C$. alternifolius living in nature aquatic environment had not been reported in previous study.

In the present study, we analyzed the AMF colonization rates of the three kinds of plant roots collected from the Donghu Lake and Nanhu Lake. Our result showed a high level of root AMF colonization in EFBs. It is astonishing to find such a high degree of mycorrhizal colonization under long-term waterlogging. Stenlund and Charvat [33] also reported the existence of AMF in the roots of three Typha clones living in floating mats located in Lake Owasso, Minnesota, and the colonization ranged from 4 to $13 \%$.

There were differences among the root colonization of AMF in different plant species. The $\mathrm{F} \%$ and $\mathrm{M} \%$ of the four groups showed high values except EB (C. alternifolius), a species belonging to Cyperaceae which is usually thought to be a non-mycorrhizal plant family. It is possible that mycorrhizal in plant species of Cyperaceae occur in older roots and that young roots are highly resistant to AMF [54]. In this study, we collected only fine young roots to analyze AMF colonization, which might result in low $\mathrm{F} \%$ and $\mathrm{M} \%$ in $\mathrm{EB}$. The $A \%$ of $E A$ and $S B$ suggested possibly some functions of the AM symbiosis in these aquatic plants. Considering that the arbuscule is an organ for exchanging resources between the two partners [34], the 
existence of arbuscule indirectly indicated a functional symbiosis. In eutrophic waterbody, host plants not only relied on nutrients directly absorbed by their well-developed roots, but also relied on the resources supplied by AMF to satisfy normal physiological activities (Synthesis of amino acids and enzymes, cell division, photosynthesis, respiration, etc.). The additional nutrient uptake from AMF was accompanied by the promotion of plant growth, resulting in greater plant height, diameter at ground regime, leaf area and biomass [55-57]. A high M\% was recorded in SB (E. crassipes), which was consistent with the result of Gunathilakae et al. [51], de Marins et al. [53] and Bagyaraj et al. [52]. They all found high AMF colonization in roots of $E$. crassipes in aquatic ecosystems. Nevertheless, it was different from the result of Wang and Zhao [58], who sampled roots of E. crassipes free-floating in lakes and streams and found that they were non-mycorrhized. E. crassipes should theoretically be easier to colonized by AMF, due to their well-developed aerenchyma in roots. E. crassipes can transport most of the photosynthetically produced oxygen through aerenchyma to root tips, and then provides a basic survival condition for the aerobic metabolism of AMF [59]. The differences between our study and Wang and Zhao [58] might be related to different methods of AMF colonization analysis (different decolorization and dyeing process). However, even in the same plant species, the $\mathrm{F} \%$ and $\mathrm{M} \%$ were lower in SA (C. generalis collected from Nanhu Lake) compared with EA (C. generalis collected from Donghu Lake). This might be on account of the differences of environmental factors, especially $\mathrm{P}$ concentration, the $\mathrm{P}$ concentration of EA was significantly higher than that of SA (Table 1). P level in the rhizosphere has been considered as one of the main abiotic factors, which affect AMF colonization of aquatic plants [60-63]. Wang et al. [63] advised a "bell-shaped" relationship between AM fungal colonization and soil P, i.e., when soil P level is high or low enough, AM fungal colonization is inhibited, which can also occur in aquatic ecosystems.

\subsection{AM fungal communities in aquatic plant roots living in EFBs}

The community of AMF in EFBs was investigated only in the study of Stenlund and Charvat [33] using morphological method, and they found low levels of AMF were present in EFBs dominated by Typha augustifolia (averaged 4-5\%), T. xglauca (averaged 4-5\%), and T. latifolia (averaged 13\%), and the AMF identified from these communities included Glomus albidum, G. caledonium, G. etunicatum, and $G$. microcarpum. In previous studies, the distribution of AMF in other aquatic ecosystems was extensively studied using morphological methods, and Glomus was found to be the dominant AMF, meanwhile Acaulospora, Scutellospora, and Gigaspora were also identified [63-66]. The novel species of Rhizoglomus melanum was isolated from the rhizosphere of isoëtid vegetation in the freshwater lake Avsjøen located at Central Norway [67]. Molecular approaches, including RFLP, DGGE, TTGE, clone libraries and SSCP, were also used to explore the AM fungal community in aquatic ecosystems [17-21]. Calheiros et al. [19] analyzed the AM fungal communities associated with the roots of $C$. generalis, $C$. flaccida and Watsonia borbonica, inhabiting a constructed wetland (CW) which is used to treat sewage of a tourism unit, using DGGE method, and the results showed that the presence of AMF were closely related to Glomus sp., Rhizoglomus sp. and Acaulospora sp. Among these AMF species, Glomus was the 
dominant AMF genus, which was in accordance with our finding. However, the roots of $C$. generalis reported by Calheiros et al. [19] harbored a low diverse AMF which related only to Glomus sp. and Acaulospora sp.

Although the morphological and molecular methods are classical and effective, the results obtained are partial and one-sided due to their incompleteness and inaccuracy in AMF taxa detection with low abundance. It has been proved that more and more AMF abundance in aquatic habitats were discovered by NGS methods. 47 AM fungal VTs from 7 families (Glomeraceae, Archaeosporaceae, Acaulosporaceae, Gigasporaceae, Claroideoglomeraceae, Diversisporaceae and Paraglomeraceae) were found in the roots of submerged aquatic plant Lobelia dortmanna, and the dominant AMF was Glomeraceae, followed by Archaeosporaceae and Acaulosporaceae [26]. Ban et al. [38] investigated the AMF communities in roots of Phragmites australis inhabiting in three heavy metals polluted wetlands, using Illumina Mi-seq technique, and obtained a total of 258 OTUs from 235,213 sequences affiliated with 6 Glomeromycota families (Glomeraceae, Paraglomeraceae, Claroideoglomeraceae, Ambisporaceae, Archaeosporaceae, and Diversisporaceae), among which Glomeraceae and Paraglomeraceae were the most and secondmost dominant family, respectively. Xu et al. [39] investigated AMF distribution in roots of $P$. australis from two vertical-flow constructed wetlands (VFCW), utilizing the Illumina Mi-seq technique, and obtained a total of 33,031 AMF sequences, which were assigned to 54 OTUs and 17 VTs from Glomus, Claroideoglomus, Acaulospora and Gigaspora.

The AMF diversity in EFBs investigated in our study was more rich than that in Stenlund and Charvat [33], this may attributed to the different resolution and depth of identification. Compared with the studies using NGS method, the AMF diversity in our study was similar with Moora et al. [26] and Ban et al. [38], but higher than Xu et al. [39], this difference might be due to the fact that the samples of the latter were collected from a non-natural environment and the origin of AMF was single (inoculated only with Rhizoglomus Intraradices inoculum).

Our finding revealed that AMF living in the investigated EFBs related to 4 Glomeromycota genera (Glomus, Acaulospora, Claroideoglomus, and Archaeospora), and Glomus was also the dominant AMF, the results were in accordance with most studies using morphological, molecular and NGS methods. The AMF existed in roots of $C$. generalis (EA and SA) belonged to not only Glomus and Acaulospora but also Claroideoglomus and Archaeoglomus, comparing with the results of Calheiros et al. [19]. However, due to the limitations of resolution and depth of identification in that of Calheiros et al. [19], we cannot rule out the possibility of additional AMF from Claroideoglomus and Archaeoglomus. In addition, although both EFBs and CWs are aquatic ecosystems, the type of substrate in EFBs was different from those in CWs, and the content of substrate used in EFBs was lower, which may affect the AMF diversity. Cyperaceae is generally considered as a non-mycorrhizal family. Although occasional arbuscules was observed in roots of sedges by some investigators $[14,68]$ and made some authors to propose a possible classification of Cyperaceae as variable nonmycorrhizal-arbuscular mycorrhizal (NM-AM) family [54], the researchers prefer to attribute the occasional reports of AM in Cyperaceae to error in sampling, assessment and diagnoses, or non-functional arbuscules [54]. In recent years, more and more investigations have 
confirmed that several plant species from Cyperaceae family can be colonized by AMF [69]囚even in aquatic ecosystems [70]. In our study, C. alternifolius (Cyperaceae) in EB1 and EB3 showed very low AMF abundance with 14 and 31 sequences, respectively, but relative high diversity, harboring 8 OTUs and 4 VTs in EB1, and 8 OTUs and 5 VTs in EB3. However, $C$. alternifolius in EB2 showed high abundance (47557) and diversity (39 OTUs). The AM fungal community in roots of $C$. alternifolius indicated that NGS techniques were effective to discover the rare species. Compared with conventional morphological identification, NGS techniques showed more accurate identification ability due to the higher resolution. Now we have confirmed the presence of AMF in roots of $C$. alternifolius in this study. Combined with previous investigations on mycorrhizal detected in several plant species of Cyperaceae [14, 68-71], we speculated that Cyperaceae is not a non-mycorrhizal family, but a NM-AM family. The AMF abundance and diversity in roots of Cyperaceae family plant species may depend on environment variable, especially phosphate $(\mathrm{Pi})$ concentration. Lagrange et al. [71] reported a significant positive correlation among mycorrhizal colonization in Costularia comosa and soil Pi concentrations, and suggested a functional symbiosis between them. Due to the limitations of identification techniques, the researchers might not find AMF in some plant species of Cyperaceae and then considered them to be non-mycorrhizal plants. With the rapid development and popularization of NGS technology, the distribution of AMF community in the roots of mycorrhizal plants will be more accurately explored, and even detected in some plant species which were considered as non-mycorrhizal.

The difference in AM fungal community structure among different samples might be related to the different host plant species and the environment factors. Indeed, according to Su et al. [72], AMF had a strong host species preference, and the host plant species was one of main factors influencing spore density, species richness, and diversity of AMF.

AMF is known to be widespread in terrestrial ecosystems [73-76]. Almost without exception, Glomeraceae was the dominant AMF in most of terrestrial environments, which was in accordance with our finding in aquatic ecosystem. However, there are some differences between our study and the studies in terrestrial ecosystems. Diversisporaceae, Claroideoglomeraceae and Paraglomeraceae were reported as the second dominant AMF in most of terrestrial ecosystems, however, in this study, Acaulosporaceae was the second dominant species, which indicated a specific distribution of AMF in these EFBs. Yang et al. [77] found that relative abundance of OTUs belonging to the genus Acaulospora in Populus deltoids was significantly increased after short-term waterlogging. Previous studies also showed Acaulospora was a common genus in roots of aquatic plants [19, 21, 78-80], and Acaulospora was equally dominant in roots of Littorella uniflora grown in a lake [79]. In our study, AMF species belonging to genus Acaulospora were the absolutely dominant in SB2 (accounting 99.94\%), and second dominant in SB1 (35.80\%) and SB3 $(46.54 \%)$, which was similar with the results of Baar et al. [79]. Besides, the number of sequences and OTUs we obtained in this study were no less than those in most terrestrial studies, and even far more than several terrestrial studies. Therefore, AMF inhibited in EFBs was diverse and abundant, and the AM fungal communities in EFBs were different from those in terrestrial ecosystems. 


\subsection{Taxon abundance distributions}

Species abundance distribution (SAD), incorporating both species richness and abundance information, can reflect comprehensive information of a microbial community. According to the AIC values, we considered that the SAD of AMF inhabiting in the three EFBs (12 samples together) fitted the lognormal model best. AMF in different natural environment showed different SAD types, and might fit the lognormal, broken stick or niche preemption models [38, 81, 82]. The finding in the present study was in accordance with previous observations [45, 81-83]. For the four groups, EA and SB showed best fit to lognormal model, however, EB and SA showed best fit to Zipf model. Obviously, the different results of groups EB and SA attributed to the most abundant OTU397 (Glomus LES06 VTX00310), which accounted for $92 \%$ of the total sequences in EB, and the most abundant OTU914 (Glomus sp. MH559174.1), which accounted for $97 \%$ of the total sequences in SA. There were absolutely dominant OTUs in the two groups, which is also represented in Fig. S16.

The differences might also be related to the complex environmental factors in these habitats, which shaped the AM fungal community structure and abundance distribution. In this study, according to the RDA results (Fig. 6), it seems that the AMF community composition was closely related to $\mathrm{pH}, \mathrm{N}$ and $\mathrm{P}$ in the two eutrophic lakes, which was in accordance with previous studies [20, 84, 85]. AMF can promote absorption of $\mathrm{N}$ and Pi by plants. After being taken up through the ammonium transport proteins, nitrate transport proteins and $\mathrm{Pi}$ transport proteins in the extraradical mycelium (ERM), the inorganic $\mathrm{N}$ and $\mathrm{Pi}$ are incorporated into amino acids and ATP, respectively, and then translocated from the ERM to the intraradical mycelium (IRM) as arginine and polyphosphate (poly-P). The ammonia and $\mathrm{Pi}$ are released from arginine and poly-P breakdown and eventually transport into the host root cells [86-88]. The AMF community composition was positively correlated with TN and TP in most groups, suggesting that this mutualistic symbiosis played an important role in eutrophic water and also effect both parties forming mycorrhizal symbionts. The correlations between AMF communities and environmental factors were different in different groups, different genera of AMF have different adaptability to ecological environment. Not only unilateral effects of environmental factors, but also Niche differentiation caused by host and interspecific interaction, will then resulted in different SADs types of AM fungal community.

However, the present study was conducted at a small spatial and temporal scale, and thus the SAD types might be scale dependent. The AM fungal SAD at landscape or continental scale would be decided by their biogeography, species ranges sizes, and the interaction between locally abundant taxa and widespread generalist species [81].

\subsection{Overdominance and inequitability}

Of the total abundance of AM fungal community examined across the three EFBs in this study, the dominant AM fungal taxon (OTU393, Acaulospora Alguacil10 Aca2 VTX00028) accounted for $16 \%$. Fierer et al. [89] analyzed the bacterial communities in soil and rhizosphere, and found the most dominant 
bacterial OTU accounted for $18 \%$ to $26 \%$ of the total abundance, a similar level was also observed in phytoplankton communities [90]. The level of dominance found in this study was similar to the typical level of dominance of the above mentioned bacterial and phytoplankton taxa. However, for 4 groups, the dominant AM fungal taxon occupied 17\% (EA, OTU960, Glomus irregular VTX00114), 92\% (EB, OTU397, Glomus LES06 VTX00310), 90\% (SA, OTU914, Glomus sp.) and 35\% (SB, OTU393, Acaulospora Alguacil10 Aca2 VTX00028) of the total abundance, respectively. This was similar to the results obtained by Dumbrell et al. [81], who reported that the dominant AM fungal taxon accounted for an average of $40 \%$ of the total abundance of all AM fungal community examined. In addition, the dominant species of AMF in the 4 groups were different, which indicated that the role of stochastic events in producing a community heavily dominated by one or two species that by chance had an unusually high recruitment rate [91].

\subsection{Functions and applications of AMF in environmental remediation}

In aquatic and wetland habitats, the functions of AMF have not been extensively studied. Currently known, AMF can affect the composition, succession, and diversity of the plant community [63, 92], promote plant growth and nutrient absorption [55, 62, 93], and improve the purification effect of the heavy metals polluted wastewater $[39,51,57]$.

Over the years, as an economical and environmentally friendly bioremediation technology, AMF-plant combination bioremediation technology has been widely studied and applied in situ soil remediation. However, only a few studies had explored the ecological functions of AMF living in aquatic habitats and technical installations which were used for the phytoremediation of wastewater. Fester [94] investigated AMF diversity in roots of $P$. australis from a constructed wetland used to decontaminate groundwater, and found a rich diversity of AMF in the inlet part of the wetland. This laid a good foundation for the researches on biodiversity and distribution of AMF in wastewater treatment. In recent years, Luo et al. [95] proved that AMF could establish a good symbiotic association with cattails in aquatic environment, and had the potential to enhance the tolerance of aquatic plants to environmental pollution and to remedy heavy metal pollution. Similarly, Xu et al. [39] constructed two VFCW planting with $P$. australis, and investigated the roles of AMF played in purification of heavy metals polluted wastewater. The results showed that the VFCW2 which inoculated with $R$. intraradices inoculum possessed higher removal efficiencies of $\mathrm{Cd}$ and Zn than VFCW1 (CK), which indicated that AMF might plays a role in removing heavy metals from CWs. The researches and practices of AMF in wastewater treatment have been involved not only in CWs, but also in EFBs. According to Gao et al. [96], AMF could enhance the ability of EFBs to remedy polluted water and absorb salt ions. For eutrophic water, AMF also play important roles. Fillion et al. [97] verified the efficiency of AMF associated with woody species using for fish farm effluent filtration strategies, and found that AMF might increase biomass productivity of host plants and improve P uptake. 
Unfortunately, the origins of AMF in the roots of aquatic plants in three EFBs were unknown, perhaps these AMF had colonized the roots of aquatic plants before they were transplanted to EFBs, or they came from the substrate of EFBs (carrying AMF spores, hyphae and other propagules) or from agricultural effluents discharged into the two lakes. What is striking, however, is that such a high abundance and diversity of AMF could be detected in the roots of aquatic plants inhabiting in EFBs even after several years of waterlogging. It's a normal phenomenon in nature that the same root associates with multiple different AMF species, and these AMF species would inevitably compete for limited resources, part of AMF species might eventually adapt to the eutrophic water environment, form mycorrhizal symbionts with aquatic plant roots and proliferate in large numbers, becoming the dominant AMF. At the same time, they brought benefits to the host plants, especially when the host plants were under various stress conditions. Although we didn't know exactly what those benefits were, the rich diversity and high abundance of AMF in EFBs suggested that their applications in the plant-based bioremediation of wastewater might have great potential.

\section{Conclusions}

The roots of $C$. generalis, $C$. alternifolius and $E$. crassipes living in the three EFBs harbored diverse AMF which affiliated with 4 Glomeromycota genera (Glomus, Acaulospora, Claroideoglomus, and Archaeospora). Glomus and Acaulospora were the most and second-most dominant genus, respectively. The number of sequences and OTUs we obtained in this study were far more than most of the records in terrestrial ecosystems, which indicated diverse and abundant AM fungal communities in EFBs and suggested that potential functions of AMF may act on the plant-based bioremediation of wastewater. Significant differences were found at different taxonomy levels between samples of different groups, which might be related to the complex environmental factors and strong microbial interspecies interactions in these habitats. The AMF community composition was closely related to environmental variables such as $\mathrm{pH}, \mathrm{N}$ and $\mathrm{P}$. It is expected that more and more attentions will be paid on the diversity and function of the AMF in aquatic ecosystems.

\section{Declarations}

Acknowledgment We would like to thank for Xingjian He for his help with sampling, and we also thank the anonymous reviewers and the editor of this manuscript for valuable feedback.

Funding This research was supported by "National Natural Science Foundation of China (31800420, 31670541)", "Nature Science Foundation of Hubei Province (2018CFB126)", "the Fundamental Research Funds for the Central Universities (WUT: 2019IVB046, 2020IB029)".

Data Availability All data generated or analyzed during this study are included in this published article and its supplementary information files. The raw reads have been deposited into the NCBI Sequence Read Archive (SRA) database (Accession Number: PRJNA550311). 
Code availability Not applicable.

Ethics Approval Not applicable.

Consent to participate A signed consent was taken from all the participants.

Consent for publication Written informed consent for publication was obtained from all participants.

Conflict of interest The authors declare that they have no competing interests.

\section{References}

1. Bonfante P, Genre A (2008) Plants and arbuscular mycorrhizal fungi: an evolutionary-developmental perspective. Trends Plant Sci 13: 492-498.

2. Öpik M, Davison J, Moora M, Zobel M (2014) DNA-based detection and identificaton of Glomeromycota: the virtual taxonomy of environmental sequences. Botanique 92: 135-147.

3. Kivlin SN, Hawkes CV, Treseder KK (2011) Global diversity and distribution of arbuscular mycorrhizal fungi. Soil Biol Biochem 43: 2294-2303.

4. Artursson V, Finlay RD, Jansson JK (2005) Combined bromodeoxyuridine immunocapture and terminal-restriction fragment length polymorphism analysis highlights differences in the active soil bacterial metagenome due to Glomus mosseae inoculation or plant species. Environ Microbiol 7: 1952-1966.

5. Peat HJ, Fitter AH (1993) The distribution of arbuscular mycorrhizas in the British flora. New Phytol 125: 845-854.

6. Cooke JC, Butler RH, Madole G (1993) Some observations on the vertical distribution of vesicular arbuscular mycorrhizae in roots of salt marsh grasses growing in saturated soils. Mycologia 85: 547550 .

7. Khan AG (1993) Occurrence and importance of mycorrhizae in aquatic trees of New South Wales, Australia. Mycorrhiza 3: 31-38.

8. Reid CPP, Bowen GD (1979) Effects of soil moisture on VA mycorrhizae formation and root development in Medicago. In: Harley, JL, Russell, RS (eds.) The Soil-Root Interface. Academic Press, London, pp. 211-219

9. Crawford RMM (1992) Oxygen availability as an ecological limit to plant distribution. Adv Ecol Res 23: 93-185.

10. Sculthorpe CD (1967) Biology of aquatic vascular plants. St. Martin's Press, London

11. Xu ZY, Ban YH, Jiang YH, Zhang XL, Liu XY (2016) Arbuscular mycorrhizal fungi in wetland habitats and their application in constructed wetland: a review. Pedosphere 26: 592-617.

12. Hirsch AM, Kapulnik Y (1998) Signal transduction pathways in mycorrhizal associations: comparisons with the Rhizobium-legume symbiosis. Fungal Genet Biol 23: 205-212. 
13. Hildebrandt U, Janetta K, Ouziad F, Renne B, Nawrath K, Bothe H (2001) Arbuscular mycorrhizal colonization of halophytes in Central European salt marshes. Mycorrhiza 10: 175-183.

14. Muthukumar T, Udaiyan K, Shanmughavel P (2004) Mycorrhiza in sedges-an overview. Mycorrhiza 14: 65-77.

15. D’Souza J, Rodrigues BF (2013) Seasonal diversity of arbuscular mycorrhizal fungi in mangroves of Goa, India. Int J Biodivers 2013: 1-7.

16. Weishampel PA, Bedford BL (2006) Wetland dicots and monocots differ in colonization by arbuscular mycorrhizal fungi and dark septate endophytes. Mycorrhiza 16: 495-502.

17. Wolfe BE, Mummey DL, Rillig MC, Klironomos JN (2007) Small-scale spatial heterogeneity of arbuscular mycorrhizal fungal abundance and community composition in a wetland plant community. Mycorrhiza 17: 175-183.

18. Likar M, Pongrac P, Vogel-Mikuš K, Regvar M (2009) Molecular diversity and metal accumulation of different Thlaspi praecox populations from Slovenia. Plant Soil 330: 195-205.

19. Calheiros CSC, Pereira SIA, Franco AR, Castro PML (2019) Diverse arbuscular mycorrhizal fungi (AMF) communities colonize plants inhabiting a constructed wetland for wastewater treatment. Water 11: 1535.

20. Guo X, Gong J (2014) Differential effects of abiotic factors and host plant traits on diversity and community composition of root-colonizing arbuscular mycorrhizal fungi in a salt-stressed ecosystem. Mycorrhiza 24: 79-94.

21. Nielsen KB, Kjøller R, Olsson PA, Schweiger PF, Andersen FØ, Rosendahl S (2004) Colonisation and molecular diversity of arbuscular mycorrhizal fungi in the aquatic plants Littorella uniflora and Lobelia dortmanna in southern Sweden. Mycol Res 108: 616-625.

22. Pimentel T, Marcelino J, Ricardo F, Soares A, Calado R (2017) Bacterial communities 16S rDNA fingerprinting as a potential tracing tool for cultured seabass Dicentrarchus labrax. Sci Rep 7: 11862.

23. Douterelo I, Boxall JB, Deines P, Sekar R, Fish KE, Biggs CA (2014) Methodological approaches for studying the microbial ecology of drinking water distribution systems. Water Res 65: 134-156.

24. Zinger L, Gobet A, Pommier T (2012) Two decades of describing the unseen majority of aquatic microbial diversity. Mol Ecol 21: 1878-1896.

25. Silvani VA, Colombo RP, Scorza MV, Bidondo LF, Rothen CP, Scotti A, Fracchia S, Godeas A (2017) Arbuscular mycorrhizal fungal diversity in high-altitude hypersaline Andean wetlands studied by 454sequencing and morphological approaches. Symbiosis 72: 1-10.

26. Moora M, Öpik M, Davison J, Jairus T, Vasar M, Zobel M, Eckstein RL (2016) AM fungal communities inhabiting the roots of submerged aquatic plant Lobelia dortmanna are diverse and include a high proportion of novel taxa. Mycorrhiza 26: 735-745.

27. Liu L, Wang S, Ji J, Xie Y, Shi X, Chen J (2020) Characteristics of microbial eukaryotic community recovery in eutrophic water by using ecological floating beds. Sci Total Environ 711: 134551. 
28. Wu Q, Hu Y, Li S, Peng S, Zhao H (2016) Microbial mechanisms of using enhanced ecological floating beds for eutrophic water improvement. Bioresour Technol 211: 451-456.

29. Lyu JC, Lin GH, Fan ZY, Lin WX, Dai Z (2020) Suitable plant combinations for ecological floating beds in eutrophic subtropical coastal wetlands under different salinities: experimental evidences. Int J Environ Sci Te 17: 4505-4516.

30. Chen Z, Kuschk P, Reiche N, Borsdorf H, Kastner M, Koser H (2012) Comparative evaluation of pilot scale horizontal subsurface-flow constructed wetlands and plant root mats for treating groundwater contaminated with benzene and MTBE. J Hazard Mater 209-210: 510-515.

31. Richter J, Wiessner A, Zehnsdorf A, Müller JA, Kuschk P (2016) Injection of hydrogen gas stimulates acid mine drainage treatment in laboratory-scale hydroponic root mats. Eng Life Sci 16: 769-776.

32. Chen Z, Cuervo DP, Muller JA, Wiessner A, Koser H, Vymazal J, Kastner M, Kuschk P (2016) Hydroponic root mats for wastewater treatment-a review. Environ Sci Pollut Res Int 23: 15911-15928.

33. Stenlund DL, Charvat ID (1994) Vesicular arbuscular mycorrhizae in floating wetland mat communities dominated by Typha. Mycorrhiza 4: 131-137.

34. Smith SE, Read DJ (2008) Mycorrhizal symbiosis. Academic Press, New York

35. EPAC (2002) Analysis methods for water and wastewater. Chinese Environmental Science Press Beijing

36. Phillips M, Hayman DS (1970) Improved procedures for clearing roots and staining parasitic and vesicular-arbuscular mycorrhizal fungi for rapid assessment of infection. Trans Br Mycol Soc 55: 158-161.

37. Trouvelot A, Kough JL, Gianinazzi-Pearson V (1986) Estimation of VA mycorrhizal infection levels. Research for methods having a functional significance. Physiological and Genetical Aspects of Mycorrhizae. Aspects physiologiques et genetiques des mycorhizes, Dijon (France), 1-5 Jul 1985. /1INRA.

38. Ban Y, Jiang Y, Li M, Zhang X, Zhang S, Wu Y, Xu Z (2017) Homogenous stands of a wetland grass living in heavy metal polluted wetlands harbor diverse consortia of arbuscular mycorrhizal fungi. Chemosphere 181: 699-709.

39. Xu Z, Wu Y, Jiang Y, Zhang X, Li J, Ban Y (2018) Arbuscular mycorrhizal fungi in two vertical-flow wetlands constructed for heavy metal-contaminated wastewater bioremediation. Environ Sci Pollut Res Int 25: 12830-12840.

40. Lee J, Lee S, Young JP (2008) Improved PCR primers for the detection and identification of arbuscular mycorrhizal fungi. Fems Microbiol Ecol 65: 339-349.

41. Lumini E, Orgiazzi A, Borriello R, Bonfante P, Bianciotto V (2010) Disclosing arbuscular mycorrhizal fungal biodiversity in soil through a land-use gradient using a pyrosequencing approach. Environ Microbiol 12: 2165-2179.

42. Cui XC, Hu JL, Wang JH, Yang JS, Lin XG (2016) Reclamation negatively influences arbuscular mycorrhizal fungal community structure and diversity in coastal saline-alkaline land in Eastern China as revealed by Illumina sequencing. Appl Soil Ecol 98: 140-149. 
43. Caporaso JG, Lauber CL, Walters WA, Berg-Lyons D, Huntley J, Fierer N, Owens SM, Betley J, Fraser L, Bauer M (2012) Ultra-high-throughput microbial community analysis on the Illumina HiSeq and MiSeq platforms. ISME J 6: 1621-1624.

44. Caporaso JG, Kuczynski J, Stombaugh J, Bittinger K, Bushman FD, Costello EK, Fierer N, Pena AG, Goodrich JK, Gordon JI (2010) QIIME allows analysis of high-throughput community sequencing data. Nat Methods 7: 335-336.

45. Moebius-Clune DJ, Moebius-Clune BN, van Es HM, Pawlowska TE (2013) Arbuscular mycorrhizal fungi associated with a single agronomic plant host across the landscape: Community differentiation along a soil textural gradient. Soil Biol Biochem 64: 191-199.

46. Lozupone C, Knight R (2005) UniFrac: a new phylogenetic method for comparing microbial communities. Appl Environ Microbiol 71: 8228-8235.

47. Magurran A (2004) Measuring biological diversity. Blackwells, Oxford

48. El Faiz A, Duponnois R, Winterton P, Ouhammou A, Meddich A, Boularbah A, Hafidi M (2015) Effect of different amendments on growing of Canna indica L. inoculated with AMF on mining substrate. Int $J$ Phytoremediat 17: 503-513.

49. Dong J, Wang L, Ma F, Yang JX, Zhang X, Zhao T, Qi SS (2017) Effects of Funnelliformis mosseae inoculation on alleviating atrazine damage in Canna indica L. var. flava Roxb. Int J Phytoremediat 19: 46-55.

50. Aziz Al, Abd Al-Latif AS (2018) The effect of mycorrhiza (Glomus mosseae) on the growth and flowering of Canna generalis cultivated in the soil contaminated with lead and cadmium. J Res Ecol 6: 1853-1866.

51. Gunathilakae N, Yapa N, Hettiarachchi R (2018) Effect of arbuscular mycorrhizal fungi on the cadmium phytoremediation potential of Eichhornia crassipes (Mart.) Solms. Groundw Sustain Dev 7: 477-482.

52. Bagyaraj DJ, Manjunath A, Patil RB (1979) Occurrence of vesicular-arbuscular mycorrhizas in some tropical aquatic plants. Trans Br Mycol Soc 72: 164-167.

53. de Marins JF, Carrenho R, Thomaz SM (2009) Occurrence and coexistence of arbuscular mycorrhizal fungi and dark septate fungi in aquatic macrophytes in a tropical river-floodplain system. Aquat Bot 91: 13-19.

54. Brundrett MC (2009) Mycorrhizal associations and other means of nutrition of vascular plants: understanding the global diversity of host plants by resolving conflicting information and developing reliable means of diagnosis. Plant Soil 320: 37-77.

55. Hu S, Chen Z, Vosatka M, Vymazal J (2020) Arbuscular mycorrhizal fungi colonization and physiological functions toward wetland plants under different water regimes. Sci Total Environ 716: 137040.

56. Ingraffia R, Amato G, Frenda AS, Giambalvo D (2019) Impacts of arbuscular mycorrhizal fungi on nutrient uptake, N2 fixation, N transfer, and growth in a wheat/faba bean intercropping system. PLoS One 14: e0213672. 
57. Xu Z, Wu Y, Xiao Z, Ban Y, Belvett N (2019) Positive effects of Funneliformis mosseae inoculation on reed seedlings under water and TiO2 nanoparticles stresses. World J Microb Biot 35: 81.

58. Wang K, Zhao ZW (2006) Occurrence of arbuscular mycorrhizas and dark septate endophytes in hydrophytes from lakes and streams in Southwest China. Hydro Biology 99: 29-37.

59. Tanner CC, Clayton JS (1985) Vesicular arbuscular mycorrhiza studies with a submerged aquatic plant. Trans Br Mycol Soc 85: 683-688.

60. White JA, Charvat I (1999) The mycorrhizal status of an emergent aquatic, Lythrum salicaria L., at different levels of phosphorus availability. Mycorrhiza 9: 191-197.

61. Tang F, White JA, Charvat I (2001) The effect of phosphorus availability on arbuscular mycorrhizal colonization of Typha angustifolia. Mycologia 93: 1042-1047.

62. Xie Xy, Weng Bs, Cai Bp, Dong Yr, Yan Cl (2014) Effects of arbuscular mycorrhizal inoculation and phosphorus supply on the growth and nutrient uptake of Kandelia obovata (Sheue, Liu \& Yong) seedlings in autoclaved soil. Appl Soil Ecol 75: 162-171.

63. Wang Y, Qiu Q, Yang Z, Hu Z, Tam NF-Y, Xin G (2009) Arbuscular mycorrhizal fungi in two mangroves in South China. Plant Soil 331: 181-191.

64. Choudhury B, Kalita MC, Azad P (2010) Distribution of arbuscular mycorrhizal fungi in marshy and shoreline vegetation of Deepar Beel Ramsar Site of Assam, India. World J Microb Biot 26: 1965-1971.

65. Radhika KP, Rodrigues BF (2007) Arbuscular Mycorrhizae in association with aquatic and marshy plant species in Goa, India. Aquat Bot 86: 291-294.

66. Miller SP, Bever JD (1999) Distribution of arbuscular mycorrhizal fungi in stands of the wetland grass Panicum hemitomon along a wide hydrologic gradient. Oecologia 119: 586-592.

67. Sudová R, Sýkorová Z, Rydlová J, Čtvrtlíková M, Oehl F (2015) Rhizoglomus melanum, a new arbuscular mycorrhizal fungal species associated with submerged plants in freshwater lake Avsjøen in Norway. Mycol Prog 14: 9.

68. Harley JL, Harley EL (1987) A Check-List of Mycorrhiza in the British Flora. New Phytol 105: 1-102.

69. Veselkin DV, Konoplenko MA, Betekhtina AA (2014) Means for soil nutrient uptake in sedges with different ecological strategies. Russ J Ecol+ 45: 547-554.

70. Fusconi A, Mucciarelli M (2018) How important is arbuscular mycorrhizal colonization in wetland and aquatic habitats? Environ Exp Bot 155: 128-141.

71. Lagrange A, L'Huillier L, Amir H (2013) Mycorrhizal status of Cyperaceae from New Caledonian ultramafic soils: effects of phosphorus availability on arbuscular mycorrhizal colonization of Costularia comosa under field conditions. Mycorrhiza 23: 655-661.

72. Su YY, Sun X, Guo LD (2011) Seasonality and host preference of arbuscular mycorrhizal fungi of five plant species in the inner Mongolia steppe, China. Braz J Microbiol 42: 57-65.

73. De Beenhouwer M, Muleta D, Peeters B, Van Geel M, Lievens B, Honnay O (2014) DNA pyrosequencing evidence for large diversity differences between natural and managed coffee mycorrhizal fungal communities. Agron Sustain Dev 35: 241-249. 
74. Ciccolini V, Ercoli L, Davison J, Vasar M, Öpik M, Pellegrino E (2016) Land-use intensity and host plant simultaneously shape the composition of arbuscular mycorrhizal fungal communities in a Mediterranean drained peatland. Fems Microbiol Ecol 9: 1-13.

75. Rodríguez-Echeverría S, Teixeira H, Correia M, Timóteo S, Heleno R, Öpik M, Moora M (2017) Arbuscular mycorrhizal fungi communities from tropical Africa reveal strong ecological structure. New Phytol 213: 380-390.

76. Sun YQ, Zhang X, Wu ZX, Hu YJ, Wu SL, Chen BD (2016) The molecular diversity of arbuscular mycorrhizal fungi in the arsenic mining impacted sites in Hunan Province of China. J Environ Sci 39: 110-118.

77. Yang Hs, Koide RT, Zhang Q (2016) Short-term waterlogging increases arbuscular mycorrhizal fungal species richness and shifts community composition. Plant Soil 404: 373-384.

78. Wirsel SGR (2004) Homogenous stands of a wetland grass harbour diverse consortia of arbuscular mycorrhizal fungi. Fems Microbiol Ecol 48: 129-138.

79. Baar J, Paradi I, Lucassen ECHET, Hudson-Edwards KA, Redecker D, Roelofs JGM, Smolders AJP (2011) Molecular analysis of AMF diversity in aquatic macrophytes: A comparison of oligotrophic and utra-oligotrophic lakes. Aquatic Botany 94: 53-61.

80. Wang Y, Li Y, Bao X, Björn LO, Li S, Olsson PA (2016) Response differences of arbuscular mycorrhizal fungi communities in the roots of an aquatic and a semiaquatic species to various flooding regimes. Plant Soil 403: 361-373.

81. Dumbrell AJ, Nelson M, Helgason T, Dytham C, Fitter AH (2010) Idiosyncrasy and overdominance in the structure of natural communities of arbuscular mycorrhizal fungi: is there a role for stochastic processes? J Ecol 98: 419-428.

82. Unterseher M, Jumpponen A, Öpik M, Tedersoo L, Moora M, Dormann CF, Schnittler M (2011) Species abundance distributions and richness estimations in fungal metagenomics-lessons learned from community ecology. Mol Ecol 20: 275-285.

83. Nielsen KB, Kjøller R, Bruun HH, Schnoor TK, Rosendahl S (2016) Colonization of new land by arbuscular mycorrhizal fungi. Fungal Ecol 20: 22-29.

84. Wang C, Tian B, Yu Z, Ding J (2020) Effect of different combinations of phosphorus and nitrogen fertilization on arbuscular mycorrhizal fungi and aphids in wheat. Insects 11: 365.

85. Xiang D, Verbruggen E, Hu Y, Veresoglou SD, Rillig MC, Zhou W, Xu T, Li H, Hao Z, Chen Y, Chen B (2014) Land use influences arbuscular mycorrhizal fungal communities in the farming-pastoral ecotone of northern China. New Phytol 204: 968-978.

86. Govindarajulu M, Pfeffer PE, Jin H, Abubaker J, Douds DD, Allen JW, Bucking H, Lammers PJ, Shachar-Hill Y (2005) Nitrogen transfer in the arbuscular mycorrhizal symbiosis. Nature 435: 819823.

87. Javot H, Pumplin N, Harrison MJ (2007) Phosphate in the arbuscular mycorrhizal symbiosis: transport properties and regulatory roles. Plant Cell Environ 30: 310-322. 
88. Kikuchi Y, Hijikata N, Ohtomo R, Handa Y, Kawaguchi M, Saito K, Masuta C, Ezawa T (2016) Aquaporin-mediated long-distance polyphosphate translocation directed towards the host in arbuscular mycorrhizal symbiosis: application of virus-induced gene silencing. New Phytol 211: 1202-1208.

89. Fierer N, Breitbart M, Nulton J, Salamon P, Lozupone C, Jones R, Robeson M, Edwards RA, Felts B, Rayhawk S, Knight R, Rohwer F, Jackson RB (2007) Metagenomic and small-subunit rRNA analyses reveal the genetic diversity of bacteria, archaea, fungi, and viruses in soil. Appl Environ Microbiol 73: 7059-7066.

90. Venrick EL (1990) Phytoplankton in an oligotrophic ocean: species structure and interannual variability. Ecology 71: 1547-1563.

91. Poulin R, Luque JL, Guilhaumon F, Mouillot D (2008) Species abundance distributions and numerical dominance in gastrointestinal helminth communities of fish hosts. J Helminthol 82: 193-202.

92. Zhang Q, Sun Q, Koide RT, Peng Z, Zhou J, Gu X, Gao W, Yu M (2014) Arbuscular mycorrhizal fungal mediation of plant-plant interactions in a marshland plant community. Sci World J 2014: 923610.

93. Neto D, Carvalho LM, Cruz C, Martins-Loução MA (2006) How do mycorrhizas affect C and N relationships in flooded Aster tripolium plants? Plant Soil 279: 51-63.

94. Fester T (2013) Arbuscular mycorrhizal fungi in a wetland constructed for benzene-, methyl tert-butyl ether-and ammonia-contaminated groundwater bioremediation. Microb Biotechnol 6: 80-84.

95. Luo PC, Li H, Wang SG (2016) Effect of arbuscular mycorrhiza (AM) on tolerance of Cattail on Cd stress in aquatic environment. Environ Sci 37: 750-755 (in Chinese).

96. Gao P, Wang X, Sang Y, Wang S, Dai D (2020) AM fungi enhance the function of ecological floating bed in the treatment of saline industrial wastewater. Environ Sci Pollut Res Int 27: 16656-16667.

97. Fillion M, Brisson J, Guidi W, Labrecque M (2011) Increasing phosphorus removal in willow and poplar vegetation filters using arbuscular mycorrhizal fungi. Ecol Eng 37: 199-205.

\section{Tables}

Table 1 The COD, nitrogen and phosphorus concentrations of the sampling water

\begin{tabular}{|c|c|c|c|c|c|c|c|}
\hline Samplings & $\mathrm{COD}_{\mathrm{Mn}}(\mathrm{mg} / \mathrm{L})$ & $\mathrm{TN}(\mathrm{mg} / \mathrm{L})$ & $\mathrm{NO}_{3}{ }^{-}-\mathrm{N}(\mathrm{mg} / \mathrm{L})$ & $\mathrm{NH}_{4}{ }^{+}-\mathrm{N}(\mathrm{mg} / \mathrm{L})$ & $\mathrm{NO}_{2}{ }^{-}-\mathrm{N}(\mathrm{mg} / \mathrm{L})$ & $\mathrm{TP}(\mathrm{mg} / \mathrm{L})$ & $\mathrm{IP}(\mathrm{mg} / \mathrm{L})$ \\
\hline EA & $4.72(0.75) \mathrm{a}$ & $11.35(0.05) \mathrm{a}$ & $0.56(0.02) \mathrm{c}$ & $9.28(0.11) \mathrm{a}$ & $0.12(0.00) \mathrm{a}$ & $0.77(0.12) a$ & $0.72(0.01) \mathrm{a}$ \\
\hline EB & $4.72(0.75) \mathrm{a}$ & $11.35(0.05) \mathrm{a}$ & $0.56(0.02) \mathrm{c}$ & $9.28(0.11) \mathrm{a}$ & $0.12(0.00) \mathrm{a}$ & $0.77(0.12) a$ & $0.72(0.01) a$ \\
\hline SA & $5.70(0.92) \mathrm{a}$ & $4.37(0.26) \mathrm{b}$ & $1.37(0.00) \mathrm{b}$ & $2.01(0.11) \mathrm{c}$ & $0.06(0.00) c$ & $0.09(0.00) \mathrm{b}$ & $0.10(0.01) \mathrm{b}$ \\
\hline SB & $4.79(0.72) \mathrm{a}$ & $3.96(0.13) \mathrm{c}$ & $2.10(0.16) \mathrm{a}$ & $2.51(0.40) \mathrm{b}$ & $0.09(0.00) \mathrm{b}$ & $0.09(0.00) \mathrm{b}$ & $0.03(0.03) \mathrm{c}$ \\
\hline
\end{tabular}

EA, Canna generalis collected from Donghu Lake; EB, Cyperus alternifolius collected from Donghu Lake; SA, C. generalis collected from Nanhu Lake; SB, Eichhornia crassipes collected from Nanhu Lake. TN, total nitrogen; TP, total phosphorus; IP, inorganic 
phosphorus. Data are means (S.E.) from three replicate samples, letters show significant differences between samples according to Duncan's test $(p<0.001)$.

Table 2 The on-line parameters of the sampling water measured in situ

\begin{tabular}{cccccccccc}
\hline Samplings & $\mathrm{T}\left({ }^{\circ} \mathrm{C}\right)$ & $\mathrm{pH}$ & $\mathrm{EC}(\mu \mathrm{s} / \mathrm{cm})$ & $\mathrm{TDS}(\mathrm{g} / \mathrm{L})$ & $\mathrm{ORP}(\mathrm{mv})$ & $\mathrm{SC}(\mu \mathrm{s} / \mathrm{cm})$ & $\mathrm{S}(\mathrm{PPT})$ & $\mathrm{AT}(\mathrm{mmHg})$ & $\mathrm{DO}(\mathrm{mg} / \mathrm{L})$ \\
\hline $\mathrm{EA}$ & 7.6 & 7.53 & 334.4 & 324.35 & 110.2 & 499 & 0.24 & 764.2 & 4.44 \\
$\mathrm{~EB}$ & 7.6 & 7.53 & 334.4 & 324.35 & 110.2 & 499 & 0.24 & 764.2 & 4.44 \\
$\mathrm{SA}$ & 7.0 & 7.69 & 310.9 & 306.8 & 130.5 & 472.8 & 0.23 & 764 & 10.98 \\
$\mathrm{SB}$ & 7.3 & 7.87 & 313.7 & 307.45 & 185 & 473.1 & 0.23 & 764 & 11.35 \\
\hline
\end{tabular}

EA, Canna generalis collected from Donghu Lake; EB, Cyperus alternifolius collected from Donghu Lake; SA, C. generalis collected from Nanhu Lake; SB, Eichhornia crassipes collected from Nanhu Lake. T, temperature; EC, electrical conductivity; TDS, total dissolved solids; ORP, redox potential; SC, specific conductance; S, salinity; AT, atmosphere; DO, dissolved oxygen.

Table 3 Samples, number of obtained sequence reads (total, assigned to known Glomeromycota taxa), Chao index and number of detected AMF taxa

\begin{tabular}{|c|c|c|c|c|c|c|}
\hline $\begin{array}{l}\text { Samplings } \\
\text { Remove } \\
\text { singleton }\end{array}$ & $\begin{array}{c}\text { Total } \\
\text { sequences }\end{array}$ & $\begin{array}{c}\text { Known AMF } \\
\text { sequences }\end{array}$ & $\begin{array}{l}\text { No. of known AMF } \\
\text { OTUs }\end{array}$ & $\begin{array}{l}\text { Chao } \\
\text { index }\end{array}$ & $\begin{array}{l}\text { No. of } \\
\text { VTs }\end{array}$ & No. of taxa in NCBI \\
\hline EA1 & 54345 & 43764 & 85 & 96.00 & 4 & Glomus sp. \\
\hline EA2 & 53995 & 41684 & 103 & 114.14 & 5 & Glomus sp. \\
\hline EA3 & 61880 & 52490 & 91 & 108.27 & 4 & $\begin{array}{c}\text { Archaeospora sp., Glomus } \\
\text { sp. }\end{array}$ \\
\hline EB1 & 57115 & 14 & 8 & 10.00 & 4 & \\
\hline EB2 & 53041 & 47557 & 39 & 46.00 & 3 & Archaeospora sp. \\
\hline EB3 & 49672 & 31 & 8 & 18.00 & 5 & Archaeospora sp. \\
\hline SA1 & 55549 & 108 & 6 & 9.00 & 4 & \\
\hline SA2 & 49054 & 278 & 21 & 23.50 & 15 & Glomus sp. \\
\hline SA3 & 48025 & 5255 & 10 & 11.50 & 3 & Glomus sp. \\
\hline SB1 & 47035 & 44880 & 43 & 46.00 & 5 & Glomus sp. \\
\hline SB2 & 61121 & 57551 & 43 & 48.14 & 8 & \\
\hline SB3 & 59961 & 55187 & 90 & 93.11 & 9 & Archaeospora sp. \\
\hline total & 650793 & 348799 & 229 & & 19 & 2 \\
\hline
\end{tabular}


Table 4 Metastats analysis for the AMF abundance without singletons at genus levels in aquatic plant roots living in the three ecological floating beds based on Illumina Miseq sequencing data

\begin{tabular}{|c|c|c|c|c|c|c|}
\hline Taxon & $\begin{array}{c}\text { EA vs. EB } \\
(P \text {-value/Q- } \\
\text { value })\end{array}$ & $\begin{array}{c}\text { SA vs. SB } \\
(P \text {-value/Q- } \\
\text { value })\end{array}$ & $\begin{array}{c}\text { EA vs. SA } \\
(P \text {-value } / \mathrm{Q}- \\
\text { value })\end{array}$ & $\begin{array}{c}\text { EA vs. SB } \\
(P \text {-value/Q- } \\
\text { value })\end{array}$ & $\begin{array}{c}\text { EB vs. SA } \\
(P \text {-value/Q- } \\
\text { value })\end{array}$ & $\begin{array}{c}\text { EB vs. SB } \\
(P \text {-value /Q- } \\
\text { value })\end{array}$ \\
\hline Glomus & $0 / 0$ & $0.03 / 0.15$ & -- & $0.03 / 0.16$ & - & $0.04 / 0.36$ \\
\hline Acaulospora & -- & $0 / 0$ & -- & $0 / 0$ & -- & $0 / 0$ \\
\hline Archaeospora & -- & -- & -- & -- & -- & -- \\
\hline Claroideoglomus & -- & -- & -- & -- & -- & -- \\
\hline
\end{tabular}

Note: "--" represents the $P$-value $>0.05$ and data now shown here.

\section{Figures}
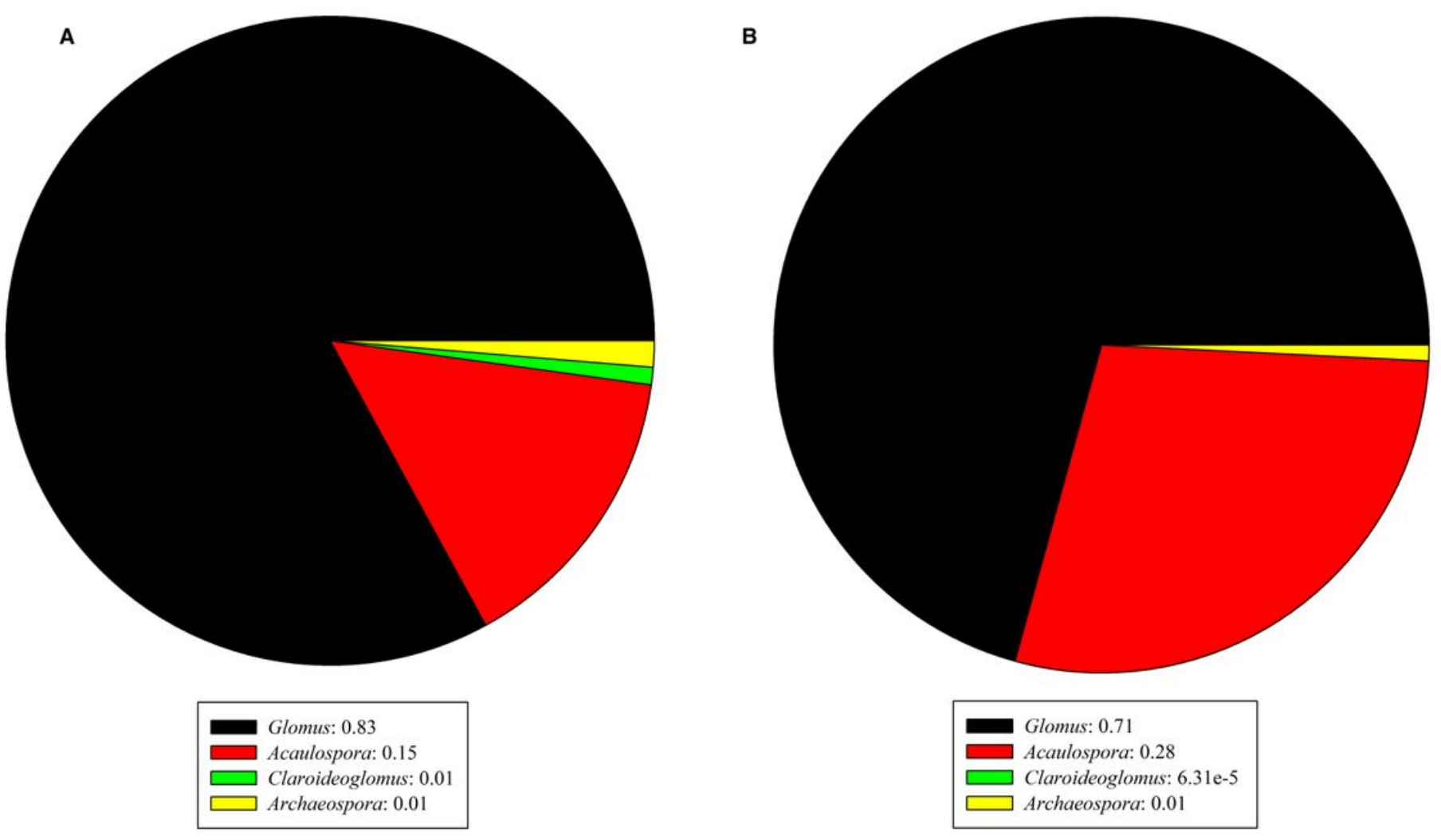

\section{Figure 1}

The proportional distributions of OTUs (a) and sequences (b) in Glomeromycota phylum detected in the three ecological floating beds 


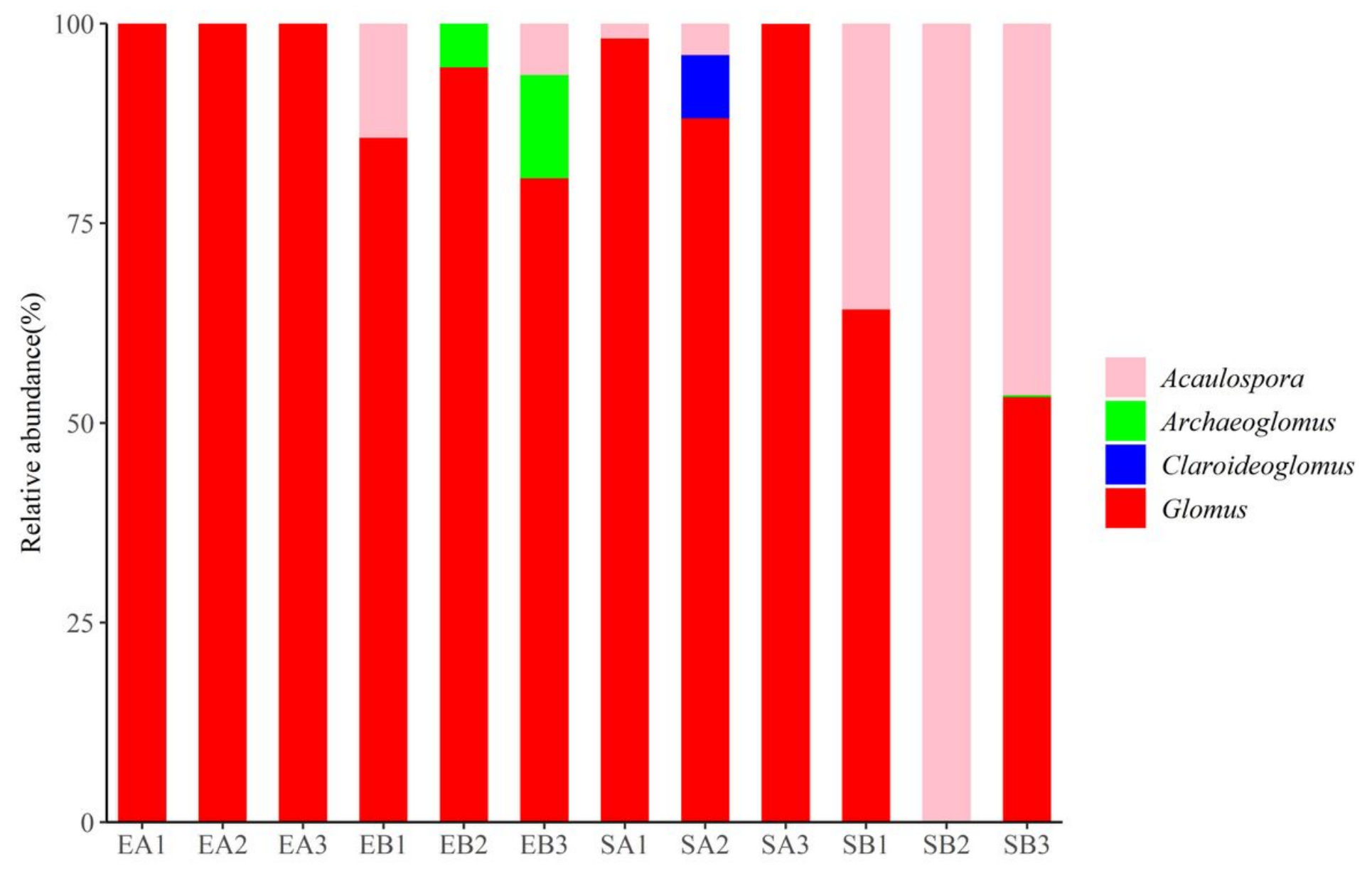

Figure 2

The proportional distributions of sequences at genus level detected in the 12 samples 


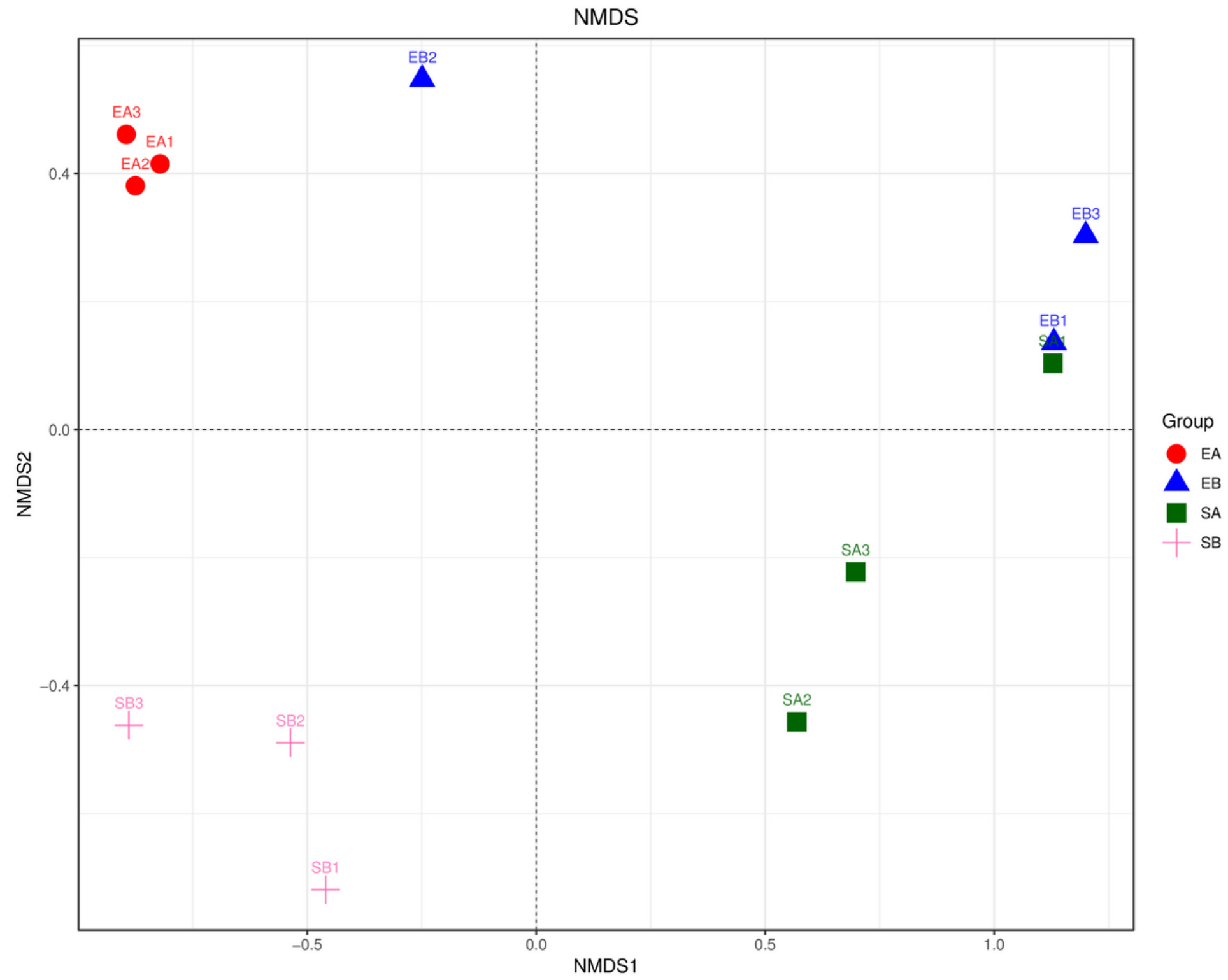

Figure 3

Two-dimensional non-metric multi-dimensional scaling (NMDS) plots of variation in AM fungal community composition of aquatic plant roots living in the three ecological floating beds 
A

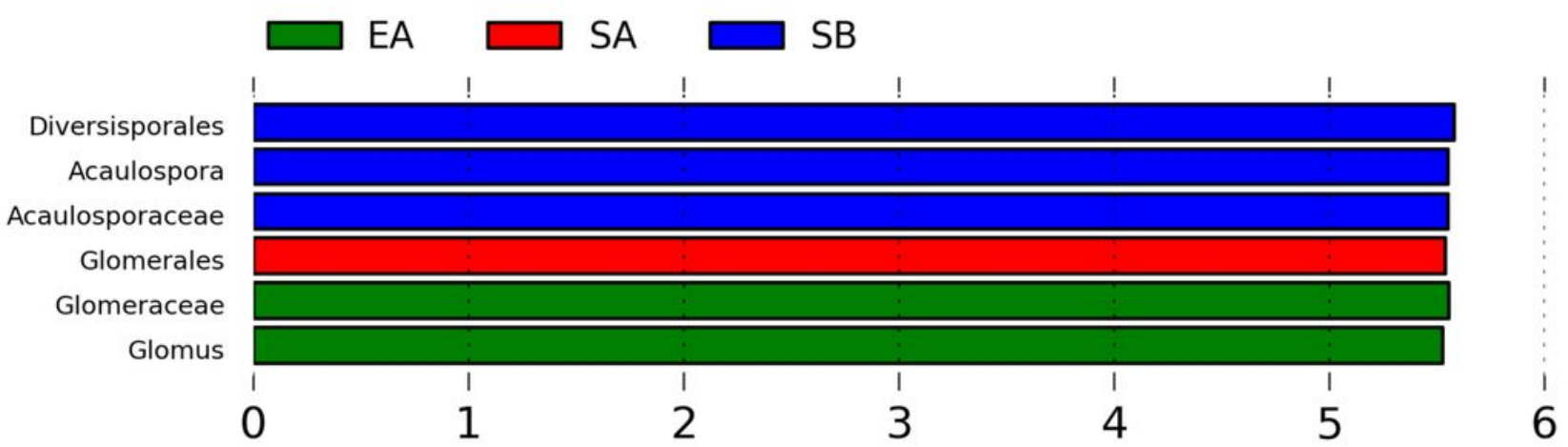

LDA SCORE $(\log 10)$

B

Fungi.Glomeromycota.Glomeromycetes.Diversisporales.Acaulosporaceae.Acaulospora

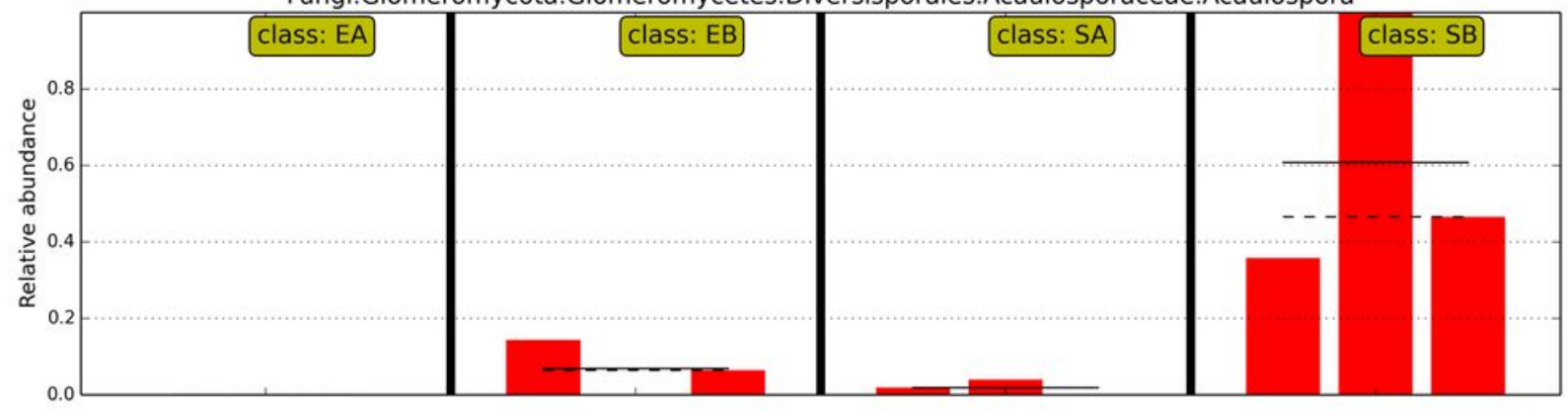

C

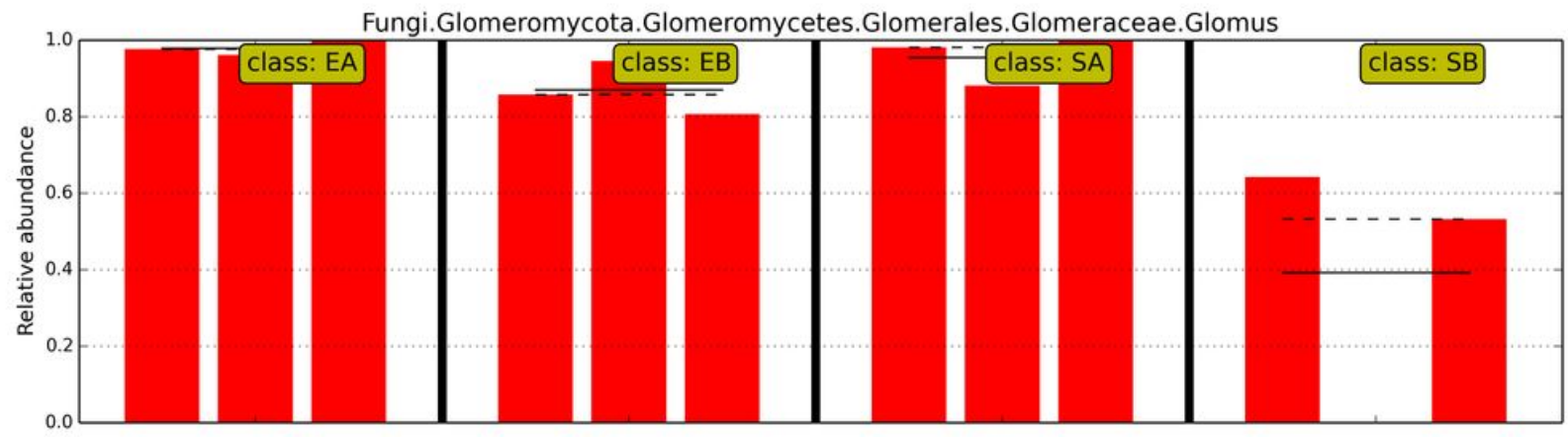

Figure 4

LEfSe results of AM fungal community in the three ecological floating beds. (a) the taxa with significant difference in the four group samples; (b) the relative abundance of Acaulospora genus in the four group samples; (c) the relative abundance of Glomus genus in the four group samples 


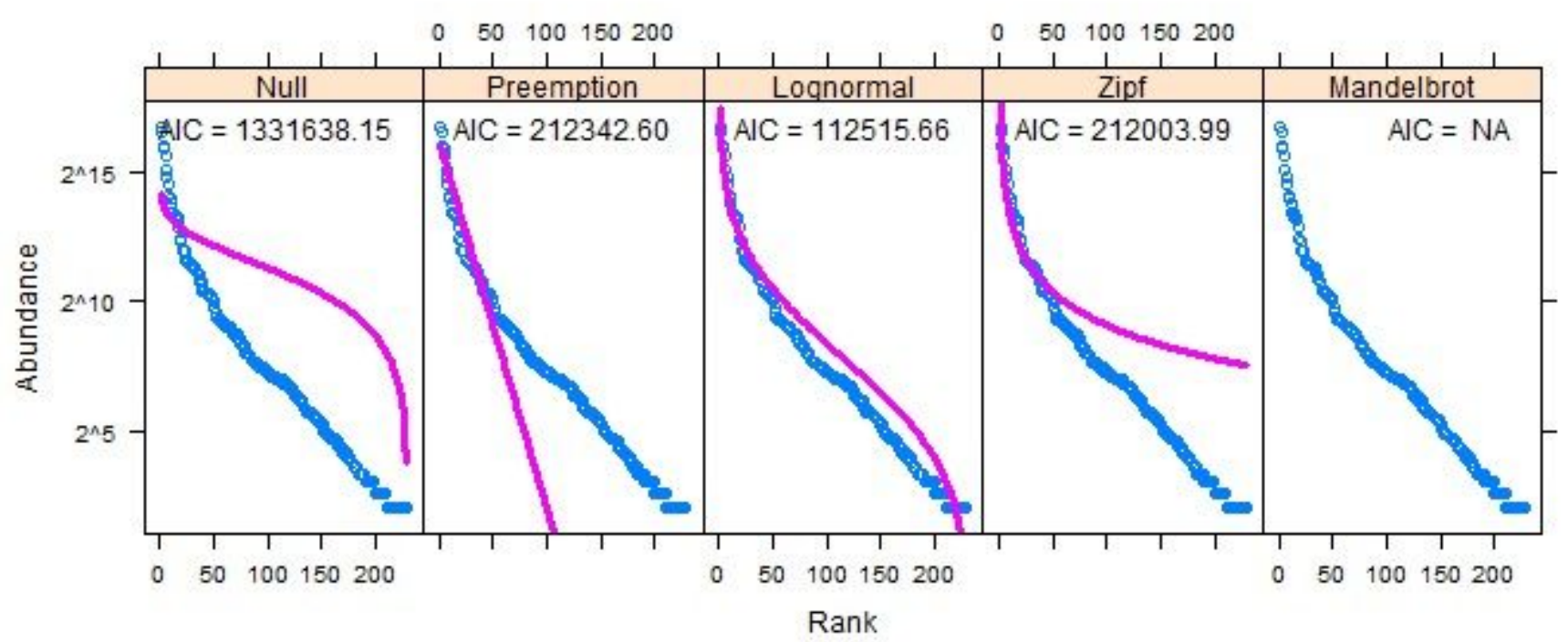

Figure 5

Statistical comparison of the fit of basic SAD models for the whole AM fungal community. Akaike's Information Criterion (AIC) and model fits for several basic SAD models, including the broken stick (null model), preemption, lognormal, Zipf, and Zipf-Mandelbrot models. AIC (lower is better) indicates that the lognormal model is the best fit 


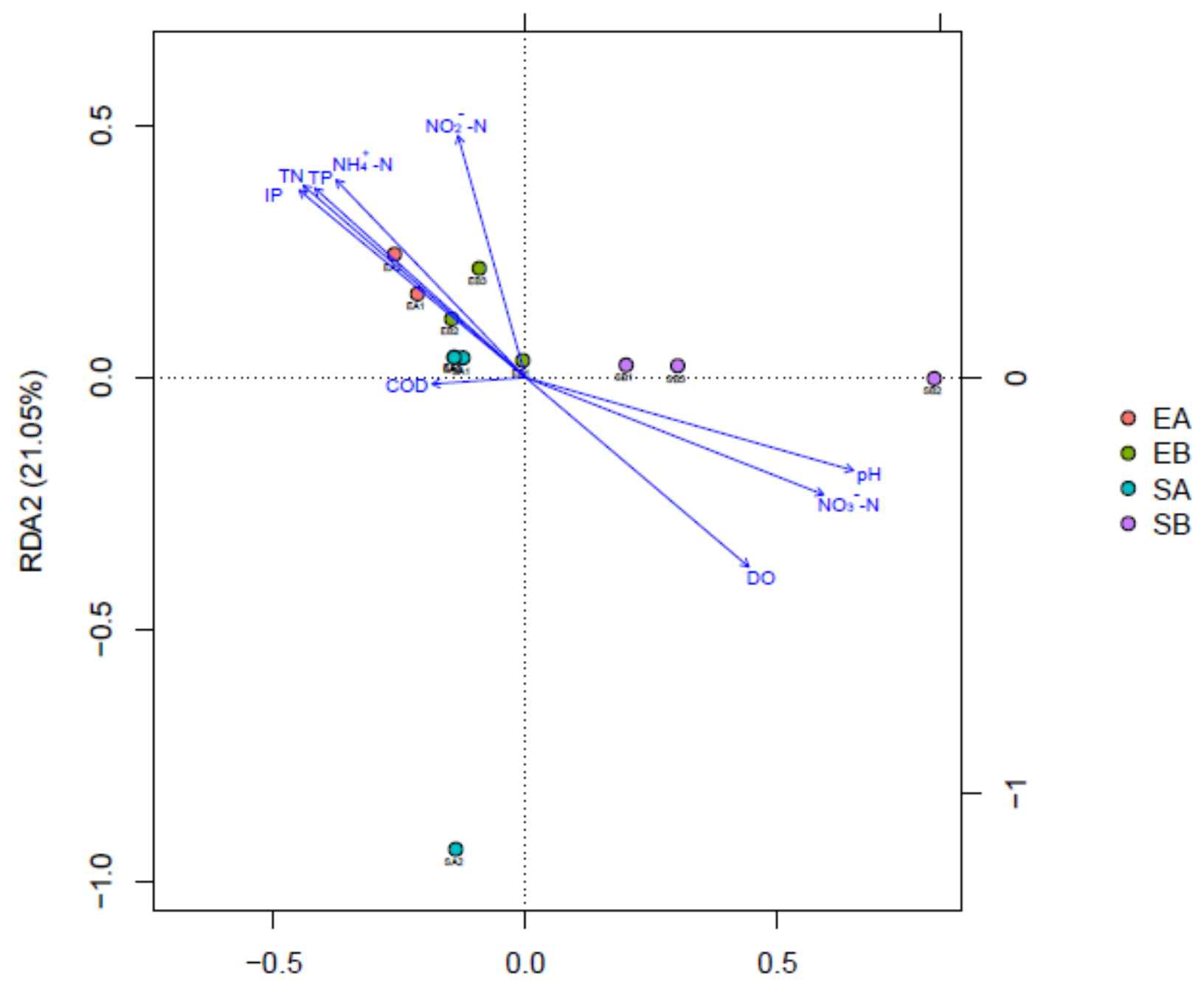

RDA1 (42.22\%)

Figure 6

Redundancy analysis (RDA) of AM fungal communities living in the three EFBs. The proxy variables were denoted by solid lines with filled arrows. TN, total nitrogen; TP, total phosphorus; IP, inorganic phosphorus; DO, dissolved oxygen; COD, chemical oxygen demand.

\section{Supplementary Files}

This is a list of supplementary files associated with this preprint. Click to download.

- ESM1.docx 